\title{
Computer-Implemented Inventions and Computer Programs - Status Quo in Slovenia and EU
}

\author{
Urška Fric \\ Faculty of Information Studies in Novo mesto \\ 8000 Novo mesto, Ljubljanska cesta 31 A, Slovenia \\ E-mail: urska.fric@fis.unm.si, https://www.fis.unm.si/si/ \\ Nina Tomić Starc \\ Agricultural Institute of Slovenia \\ 1000 Ljubljana, Hacquetova ulica 17, Slovenia \\ E-mail: nina.tomicstarc@kis.si, https://www.kis.si/
}

Keywords: computer-implemented inventions, computer programs, patent, copyright, status quo

Received: March 11, 2021

\begin{abstract}
In Slovenia, there is no legal basis for computer-implemented inventions, and in the European Union (EU) such inventions are not yet clearly defined. Over the last twenty years there have been many heated debates in the EU arena concerning a single legal instrument, but a final solution remains elusive. In Slovenia and the EU, legal protection of computer-implemented inventions thus remains on thin ice: there are certain non-obvious combinations for obtaining a patent, but ultimately the decisive factor may as well be how the patent application is written. This status quo therefore necessitates an examination of this field: to arrive at a legal basis that would regulate the patenting of computer-implemented inventions it is necessary to identify and address the most critical points. This paper deals with this issue. It starts by presenting examples of computer-implemented inventions, followed by an overview of the state of playthe status quo concerning legal protection in Slovenia and the EU. This paper also provides an overview of copyright as a legal basis for computer programs, which is the same in Slovenia and in the EU. Copyright is not exclusive, as computer programs are often also protected as trade secrets and as knowhow.

Povzetek: Prispevek obravnava računalniško izvedene izume in računalniške programe, v glavnini pa se posveča pregledu stanja oz. statusu quo pri pridobivanju pravne zaščite v Sloveniji in v EU.
\end{abstract}

\section{Introduction}

After Slovenia joined the European Union (EU), adopted the euro, and entered the Organisation for Economic Cooperation and Development (OECD), its integration into the European arena drastically improved, as did its international competitiveness. At present, information technology and digitalisation are highly developed, the country's rankings in a variety of international indices prove that Slovenia is an advanced and digitalised country. Other EU members are likewise considered advanced and digitalised, as the cutting-edge digital technologies they use make it possible to upend existing business models and create new ones, facilitate the development of new products and services, improve the efficiency and competitiveness of the economy, and contribute to socioeconomic development in general [1].

The digitalisation of the entire society and economy underpinned by intensive use of information and communication technologies has significant growth potential and as such provides the groundwork for the long-term development and competitiveness of Slovenia, the EU, and Europe in general [1]. We live in an era where information technology may be considered one of the most important industries; consequently, management of industrial property and copyright, which are in the domain of intellectual property rights and are the subject of this paper, are extraordinarily important.

Whereas the legal protection of intellectual property rights, as defined by the Convention establishing the World Intellectual Property Organization (WIPO), is defined clearly and precisely in Slovenian and EU legal instruments, this does not apply to computer-implemented inventions [2].

A computer-implemented invention means any invention the performance of which involves the use of a computer, computer network, or other programmable apparatus, the invention having one or more features that are realised wholly or partly by means of a computer program or computer programs ${ }^{1}$ [3]. Due to the recent shift

\footnotetext{
1 A computer program is an algorithm written in a programming language (e.g. C++, JavaScript, PHP, Python, etc.) that can run on a computer [4].
} 
in innovation towards things of a digital nature, computerimplemented inventions account for a large proportion of present-day inventions and creations, and as such represent an important segment of intellectual property [5]. Patents and all other intellectual property rights are the pillars of any innovation system and provide instrumental support in the development of technology and in the growth of national economies [6]. And although efforts to put in place appropriate legal instruments started over two decades ago, they ground to a halt in 2005, when, after a series of heated debates, the European Parliament voted down a proposal for a directive of the European Parliament and of the Council on the patentability of computer-implemented inventions, which the European Commission had issued in 2002 [7]. At least part of the reason why there is still no appropriate legal instrument is that such inventions are highly specific and demonstrating their technical contribution ${ }^{2}$ and industrial applicability ${ }^{3}$ may pose a significant challenge. But to a large extent, the reasons lie elsewhere - perhaps in the poor understanding of certain exemptions that apply in granting patent protection to computer-implemented inventions.

This status quo necessitates an analysis of this field and requires that the most critical points be identified and addressed in trying to create a legal basis for the patenting of computer-implemented inventions in Slovenia and the EU.

This paper presents computer-implemented inventions, the history thereof, and examples past and present. The focus is on the status quo in this field, in Slovenia and the EU, whereby we explore the possible ways of securing legal protection for computerimplemented inventions with the current legal instruments, in particular when such inventions can be patented and when they can be copyrighted. Finally, we highlight the open issues that should inform future work, in particular in the context of how and where technology transfer offices (TTO) can help accelerate the adoption of such legal instruments and improve their clarity.

\section{Computer-implemented inventions}

\subsection{Theoretical background}

Computer-implemented inventions are defined as inventions the performance of which involves the use of a computer, computer network or other programmable apparatus, the invention having one or more features that are realised wholly or partly by means of a computer program or computer programs [3]. A computerimplemented invention can cover topics related directly to information and communications technology (ICT), e.g. compiling back-ups or data compression, or it can be indirectly related to ICT and only used to control other appliances or devices [9]. Although programs for computers are as such explicitly excluded from

2 Technical contribution means a contribution to the state of the art in a field of technology that is new and not obvious to a person skilled in the art. It is assessed by consideration of the difference between the state of the art and the scope of the patent claim considered as a whole, which must comprise technical features, irrespective of whether or not these are patentability (at least at the European Patent Office (EPO)), a product or a method that is of a technical nature, i.e. it produces a further (technical) effect beyond the normal functional interaction of a program and computer, may be patentable, even if the claimed subject matter defines or at least involves a computer program [9].

\subsection{Historical review of computer- implemented inventions - some examples}

The first patent application for a computer-implemented invention in Europe was submitted in Great Britain in 1962. The application was made by British Petroleum CO. Ltd., P. V. Slee, and P. M. J. Harris. The patent for the invention A computer arranged for the automatic solution of linear programming problems was granted in 1966 [10]. The computer-implemented invention is described as a computer comprising quick-access storage, slow-access storage, and an arithmetic unit, arranged to automatically solve a linear programming problem by means of an iterative algorithm [10].

Linear programming is concerned with the control of digital data processing machines in computing solutions to that class of problems which involve simultaneous linear functions. These functions may be equations and/or inequalities descriptive of relationships characterizing a physical system, e.g. a refinery. The functions in general are satisfied by an infinite number of solutions and the digital computer is typically controlled or programmed to obtain a particular solution which will satisfy the set of functions. In the general case this particular solution is an optimum one which yields specific value for the component variables of the functions. When these values are applied to the physical system represented by the set, the system yields an optimum response. In linear programming, it has been customary heretofore, to employ the "simplex" method of controlling the-digital computer in obtaining a solution to the set of linear functions. In the "simplex" method, the set of simultaneous linear functions is arranged as a first IP Ti matrix which is stored in an appropriate storage device, the matrix comprising sets of elements which are defined as "columns" with respect to one ordinate of the matrix and as "rows" with respect to the other. In an exemplary application, the computer is controlled by the simplex linear programme device as follows, the procedure being defined in terms of matrix columns. [10]

The computer is programmed to successively scan or read the columns of the first matrix and the elements within each column to identify an element in one column which satisfies a predetermined condition. The selected column is referred to as a "pivot column" and is stored; the row therein which contains the selected element comprises the "pivot row" and the selected row and column define a "pivot point" in the matrix. [10]

accompanied by non-technical features [3]

3 Industrial applicability assumes that an invention is applicable in industry if the subject of the invention can be produced or used in any economic activity, agriculture included [8]. 
The computer is programmed to perform operations on the entire first matrix, i.e. to carry out an iteration which comprises reading and operating on the entire first matrix using the stored pivot column to produce a second matrix which is stored. The operations referred to generally comprise arithmetic operations which involve the pivot point quantity and the quantities in the other elements of the matrix. [10]

The resultant second matrix is processed in the computer in the same manner as the first matrix; if upon reading the matrix a pivot column is found, it is stored and a second iteration on the entire second matrix is performed to yield a third matrix. The process continues with further iterations until a matrix is generated which is devoid of pivot columns. This final matrix is the solution matrix and gives the values for the component variables. [10]

One example of a computer-implemented invention that is widely used every day and was granted patent protection in Europe is the electronic anti-lock braking system (ABS). In 1969 ITT Teves (Continental) unveiled an electronically supported ABS system as a premium add-on feature of the Mercedes Bens S-class, and in 2004 electronically supported ABS systems became standard on all new cars in Europe [11]. In 2019, every car regardless of market segment, price, or body style is developed with ABS in mind from the get-go. Bosch, the company that helped Mercedes develop and launch its first productionbound ABS system in 1978, explained ABS also serves as the foundation for a long list of electronic driving aids that are either common or required on all new cars. [11]

Another such example of a computer-implemented invention that could change our everyday in the near future is autonomous vehicles. Generally, an "automated vehicle" refers to a vehicle that includes certain automated functions (e.g., adaptive cruise control), whereas an "autonomous vehicle" more specifically refers to one that drives itself in most or all settings. Autonomous vehicles are rapidly evolving into one of the most transformative technologies, in part because of innovations in devices and processes historically not associated with the automotive industry, such as improved sensors and cameras, radar and Light Detection and Ranging technologies (LiDAR), artificial intelligence algorithms, and communications mechanisms for vehicle connectivity [12]. The use of such technologies in autonomous vehicles has also ushered in numerous technology and ridesharing companies as new market players in the automotive industry, which has long belonged to the traditional car manufacturers and their suppliers [12]. Patent rights are still used by most companies as their central intellectual property strategy. Traditional car makers are filing more patent applications than ever before, and technology and ridesharing companies are also building robust patent portfolios on automobile technologies. Although patents and trade secrets will likely be employed as key intellectual property mechanisms for protecting novel technologies, more

\footnotetext{
${ }^{4}$ Software is a group of computer programmes that constitute a whole in combination with hardware in a computer.

${ }^{5}$ A command line interface is an interface in the form of lines of text that shows a prompt on the screen into which a user enters a command and
}

copyright issues can be expected to arise from autonomous vehicles [12]. Although copyrights cannot be used to provide intellectual property coverage for a functionality of a proprietary software used in autonomous vehicles, copyrights will provide protections for the underlying source code of the software [12]. Given that open-source software will be used by certain companies, careful considerations must be paid by the users to comply with the open-source licenses, including the notice procedures for using the open-source software [12]. Other forms of intellectual property, such as design rights and trademarks, can also play important roles in differentiating the designs and branding of different autonomous driving technologies [12]. But before autonomous vehicles are going to be recognised as a computer-implemented invention, numerous experts have to attempt to identify intellectual property issues in the area of autonomous vehicle technology, and to navigate the complex intellectual property landscape within this rapidly developing sector [12].

\subsection{Status quo of legal framework: Slovenia}

The Slovenian Industrial Property Act (ZIL-1), which determines the types of industrial property rights and the procedures for granting and registering these rights, the legal protection of rights, and the representation of parties, stipulates in Article 10, which determines the subject matter of patent protection, that "patents shall be granted for any inventions, in all fields of technology, which are new, involve an inventive step and are susceptible of industrial application" [8]. Article 11, which determines exceptions to patent protection, stipulates that (1) "Discoveries, scientific theories, mathematical methods, and other rules, schemes, methods and processes for performing mental acts as such shall not be considered inventions within the meaning of Article 10, and that (2) A patent shall not be granted for: (a) inventions, the exploitation of which would be contrary to public order or morality; (b) inventions of surgical or diagnostic methods or methods of treatment practised directly on the living human or animal body, with the exception of inventions relating to products, in particular substances or compositions for use in any of these methods [8]. This means the Slovenian Industrial Property Act does not deal with computer-implemented inventions.

Software $^{4}$ that does not provide a technical contribution can therefore be protected only by copyright, whereby ideas cannot be copyrighted. The appearance of a command line interface ${ }^{5}$ or a graphical user interface ${ }^{6}$, on the other hand, can be protected as a registered design. At the Slovenian Intellectual Property Office (URSIL) it is possible to get a patent for computer or mobile applications, but only under the condition that a technical contribution is demonstrated.

executes it with the enter button. If the command is valid, it is executed.

${ }^{6}$ A graphical user interface displays elements such as icons and other tools. It is an interface between the user and the software. 
One such example is a patent granted in 2012 for the invention A mobile application and procedure for the processing of environmental information, which solves technical problems in preventing the generation of waste, reducing the amount of generated waste, channelling waste into reuse, appropriate disposal of individual types of waste, reducing environmental pollution and reducing the demand for the production of new raw materials that subsequently pollute the environment as waste [13]. The subject matter of the invention is carried out on a device for controlling and managing a central unit and interactive graphical menus with corresponding software are used. This provides the user with: necessary information on waste prevention, information on ways to reuse waste, information and warnings for timely waste disposal, and information on the proper separation or classification of waste, taking into account the local infrastructure and regulations of the municipality where the user lives or where the waste is generated. This was the first such patent granted in Slovenia. [13]

Another such example, also granted patent protection in 2012, is the invention A system for automatic detection and monitoring of harmful insects, which solves the problem of the time-consuming inspection of insect traps. With the help of cameras in traps it detects and monitors harmful insects. This system solves technical problem, as it enables the pest monitoring does not have to be done physically in the field. The system automatically notifies the user of events which are important to determine the optimal time to perform activities in the plantation. This saves travel costs and time for experts performing trap inspections in the field. The system also enables tracking of fruit pests as it is designed to place the trap in the tree canopy, which is also a prerequisite for effective fruit pest monitoring. [14]

The third such example is the invention $A$ system and method for printing and delivering of publications such as newspapers on-demand, which was granted patent protection in 2019 and is classified as a special purpose printing device and device combining printing and other functions. The printing and delivery system consists of at least two internet connected units and a mobile application that transmits location data to the printing and delivery device, includes account management functionalities, and sends instructions for printing and billing [15]. The mobile application actively communicates the location of the device for printing and receiving publications and allows editing subscriptions, sending commands for printing and payment. The system enables printing newspapers from different publishers in any place where the device is located. The user himself can choose the desired volume and quantity. The system is primarily intended for printing newspapers and magazines, but it can also be used for printing books or individual book chapters. [15]

\footnotetext{
7 The European Patent Convention is a multinational convention of which 38 member states participate in, including all 28 member states of the EU and 10 other non EU member states.

8 The following in particular shall not be regarded as inventions within the meaning of paragraph 1: (c) schemes, rules and methods for
}

\subsection{Status quo of legal framework: EU/EPO}

In 2002 the European Commission issued a proposal for a Directive of the European Parliament and of the Council on the patentability of computer-implemented inventions. After a series of heated debates among MEPs, the European Parliament rejected it in 2005 [3]. The adoption of this directive would have created a single set of rules for the patent protection of computer-implemented inventions in the member states.

The European Patent Convention ${ }^{7}$ established a European Patent Organisation (EPO), which is responsible to grant European patents. This is carried out by the EPO (supervised by the Administrative Council), which is not an agency or an organ of EU. It is an organ of the EPO, which has legal entity and it is an independent intergovernmental organisation. For the last 50 years, the EU's ambition to create a single, central court for the enforcement of European patents has been frustrated by the EPO's existence as an autonomous, international organisation outside the EU [16].

The European Patent Convention Stipulates in Article 52(2) (c) $)^{8}$ that programs for computers are not regarded as inventions [2]. European Patent Convention in this Article excludes computer programs from patentability. It is important we emphasize the distinction between "software patents" which are excluded according to the above mentioned Article and so-called computer-implemented inventions which are accepted at the European Patent Office [17].

The status quo thus remains the same as in Slovenia. Software that does not demonstrate a technical contribution can only be protected by copyright, which does not protect ideas. The appearance of a command line or graphical interface can be protected as a registered design, whereas a patent for computer or mobile applications can be granted if a technical contribution is demonstrated. Under EPO rules, in the event of such, the software must be connected with the hardware.

This discussion on whether a feature is technical is thus usually done under inventive step, effectively skipping the discussion for novelty if the prior art does not disclose the possibly non-technical feature. The assessment of inventive step under the European Patent Convention is normally based on the problem-solution approach. For the purpose of the problem-and-solution approach, the problem must be a technical problem which the skilled person in the particular technical field might be asked to solve at the relevant priority date. The technical problem may be formulated using an aim to be achieved in a non-technical field, and which is thus not part of the technical contribution provided by the invention to the prior art. This may be done in particular to define a constraint that has to be met (even if the aim stems from a posteriori knowledge of the invention). This means that if

performing mental acts, playing games or doing business, and programs for computers. 
an inventor comes up with a creative idea which does not solve a technical problem then the idea cannot be used to defend that the idea is inventive. The only way to argue inventive step must come from the way the idea is implemented. During the implementation the skilled man must be confronted with a technical problem which he solved in a non-obvious way. A routine programming implementation of a non-technical problem is thus not inventive. [18]

\section{Copyright and computer programs in Slovenia and EU}

\subsection{Status quo of legal framework: EU/EPO}

Computer programs are defined both in Directive 2009/24/EC of the European Parliament and of the Council of 23 April 2009 on the legal protection of computer programs (hereinafter: the Directive) [19] and the Slovenian Copyright and Related Rights Act (hereinafter: ZASP) [20]. EU member states protect computer programs by copyright the same way literary works are protected under the Bern Convention for the Protection of Literary and Artistic Works [19]. To enjoy copyright protection, no registration or other formality concerning computer program is required. Copyright protection is granted from the sole fact of the creation of the computer program [17]. While a computer program is defined by these legal instruments as a program in any form of expression and is considered a written work, software does not enjoy copyright protection. Due to the requirement that copyright protection applies to the expression of a computer program in any form, algorithms and programming languages that involve ideas and principles do not enjoy copyright protection. An algorithm is not eligible for copyright protection, because it will be considered to be of a factual nature, and therefore not an expression of the creativity of its author [17]. Preparatory design work leading to the development of a computer program is considered a computer program provided that the nature of the preparatory work is such that a computer program can result from it at a later stage.

Copyright will protect only the computer program in the form written by a programmer i.e. its source code [17]. The source code - because it is recognizable and thus analyzable by humans - is crucial from a copyright perspective, from the beginning (or whether the program is protected at all) to the end (effective enforcement and sanctioning of infringements). Special hardware programs translate the source code into machine code or machine language (machine or object code) that is directly understandable and applicable to the computer. The translation of the source code into machine code - this is a functionally necessary process for the program to run on the computer - it takes place in hardware, its consequence is to blur the source code. This is no longer comprehensible to humans and it is difficult to identify (even with special reverse engineering methods) [21].
When a computer program can be patent protected or when it can enjoy copyright protection depends on what kind of problem it resolves. If a computer program resolves a business problem, it is protected by copyright. In the event it resolves a technical problem (and meets all other criteria for patent protection), it can be protected with a patent.

\subsection{Employment and works made for hire}

The ZASP stipulates that the employer or person ordering the work is entitled to all economic rights to a computer program if it is created by an employee in the execution of his duties or by an author under a contract for a work made for hire. Economic rights and other rights of the author to such a program are assigned to the employer or person ordering the work, exclusively and without limitations. In accordance with the applicable regulations, the employer or person ordering the work and the employee (author) may agree otherwise, which has also been confirmed by the Supreme Court of the Republic of Slovenia in judgement II Ips 552/2003 [22].

In practice, however, at least regarding computer programs created in the course of an employment relationship, the worker and employer tend not to agree otherwise in the employment contract. The Directive treats the transfer of economic rights to a created computer program the same way as the ZASP, but it deals only with computer programs created in the framework of an employment relationship, it does not regulate computer programs created under a contract for a work made for hire. There are significant differences between instances when a "classic" copyrighted work is created in an employment relationship, and when a computer program is created in an employment relationship.

The ZASP also consider cases where an employee creates a copyright work that is not a computer program, in the event of which it stipulates that economic and other rights of the author to this work are exclusively assigned to the employer for a period of ten years from the completion of the work (unless the parties agree otherwise in a contract). Upon the expiration of the term, the rights revert to the employee. However, the employer can claim a new exclusive assignment of these rights, for adequate remuneration. A worker who creates a computer program in the framework of an employment relationship is therefore in a disadvantaged position compared to workers who create other copyright work in the course of their employment.

Despite the copyright protection in place for computer programs, the Directive and the ZASP do not regulate the subject matter exclusively; they allow legal protection under other branches of law [23]. For computer programs, other branches include regulations on patent protection, trademarks, protection of competition, trade secrecy, etc. Due to this non-exclusivity, and the grey area between copyright and computer-implemented inventions, computer programs are therefore often protected as trade secrets and as know-how.

Confidentiality would usually be managed using contractual tools - in the form of non-disclosure or 
confidentiality agreements (NDAs) or confidentiality clauses included in contracts. Unauthorized disclosure of an algorithm (or disclosure for unauthorized purposes) by the signatories of a confidentiality clause or agreement would result in a breach of contractual obligations, and would therefore allow you to claim damages or injunctions (or any other remedies provided by the applicable law) [17]. Know-how would also be managed using contractual tools - in the form of know-how agreements.

\section{Conclusion}

The status quo in the field of computer-implemented inventions, which are neither legally defined nor legally undefined in Slovenia and the EU, raises many open issues and provides opportunities for future work. In Slovenia it would make sense to examine at which stage TTOs can methodologically and substantively contribute to the examination and presentation of computer-implemented inventions at the level of the national patent office and to the examination of non-obvious combinations that constitute computer-implemented inventions under the ZIL-1. At the level of the EU and Europe as a whole, it is necessary to examine how we may contribute to the creation of a legal basis that would ensure uniform patenting of computer-implemented inventions.

TTOs are closely integrated with the work of organisations that produce inventions. Firstly, and foremost, we use our know-how to help researchers who create computer programs by verifying what kind of problem their program addresses and how a quality decision can consequently be made as to the protection of intellectual property (a copyright or patent).

All things considered, we believe that TTOs should at least participate in public debates and present practical examples of researchers who develop computer programs at public organisations, thereby contributing to a constructive decision-making process on the future of the protection of computer programs. However, TTO employees have to recognise steps and phases where can TTOs provide methodological and practical support in processing and presentation of computer-implemented inventions at national and EU level.

\section{Acknowledgement}

The operation is partially co-financed by the European Union from the European Regional Development Fund and the Ministry of Education, Science and Sport of the Republic of Slovenia. The operation is implemented under the Operational Program for the Implementation of European Cohesion Policy for the period 2014-2020, priority axis 1 Strengthening research, technological development and innovation.

\section{References}

[1] Republic of Slovenia, Ministry of Public Administration. (2020). Digitalizacija družbe (Digitalisation of Society). https://www.gov.si/ teme/digitalizacija-druzbe/
[2] European Patent Office. (2007). European Patent Convention (EPC 1973). https://www.epo.org/lawpractice/legal-texts/html/epc/1973/e/ar52.html

[3] EUR-Lex. Access to European Union Law. (2005). Common position (EC) No. 20/2005. European Parliament legislative resolution on the Council common position with a view to the adoption of a directive of the European Parliament and of the Council on the patentability of computerimplemented inventions. https://eurlex.europa.eu/LexUriServ/LexUriServ.do?uri=OJ:C: 2005:144E:0009:0015:EN:PDF

[4] Collins. (2020). Computer Program. https://www.collinsdictionary.com/dictionary/englis $\mathrm{h}$ /computer-program

[5] Valvoda, J. (2020). Software specific IP Issues. https://www.youtube.com/watch?v=PIYmftHTrCQ $\& \mathrm{t}=11 \mathrm{~s}$

[6] Grupp, H. (1998). Foundations of the Economics of Innovation: Theory, Measurement and Practice. Research Policy. 30, 8, (Feb. 2001), 1341-1342. DOI=https://doi.org/10.1016/S0048-7333(00)00144$\mathrm{X}$

[7] EUR-Lex. Access to European Union Law. (2006). European Parliament legislative resolution on the Council common position with a view to the adoption of a directive of the European Parliament and of the Council on the patentability of computerimplemented inventions (11979/1/2004 - C60058/2005 - 2002/0047(COD)). https://eurlex.europa.eu/legal-content/SL/TXT/PDF/ ?uri=CELEX:52005AP0275\&from $=$ EN

[8] Industrial Property Act (Official Gazette of the RS, No. 51/06 - official consolidated text, and 100/13).

[9] Neuhäusler, P. and Frietsch, R. (2019). ComputerImplemented Inventions in Europe. In Springer Handbook of Science and Technology Indicators, W. Glänzel, H. F. Moed, U. Scmoch, and M. Thelwall, Eds. Springer Nature Switzerland AG, Switzerland, Cham, 1007-1022.

[10] European Patent Office. (2020). ESPACENET. Patent Search. GB1039141 (A) - 1966-08-17. https://worldwide.espacenet.com/publicationDetails/ biblio?CC $=\mathrm{GB} \& \mathrm{NR}=1039141 \& \mathrm{KC}=\& \mathrm{FT}=\mathrm{E} \&$ local e=en_EP

[11] Glon, R. (2019). ABS Brakes helped Airlines make more Money before they helped you stop. Digital Trends. https://www.digitaltrends.com/cars/thehistory-of-abs-brakes-from-airplanes-to-cars/

[12] Kelly, B. and Chae, Y. (2018). INSIGHT: Autonomous Vehicles in the World of Intellectual Property Rights. Bloomberg Law. https://news.bloomberglaw.com/ip-law/insightautonomous-vehicles-in-the-world-of-intellectualproperty-rights

[13] Slovenian Intellectual Property Office. (2012). SI 24058 A. A Mobile Application and Procedure for the Processing of environmental Information. http://www3.uil-sipo.si/PublicationServer/ documentpdf.jsp?iDocId=27719\&iepatch=.pdf 
[14] Slovenian Intellectual Property Office. (2012). SI 23715 A. A System for automatic Detection and monitoring of harmful Insects. http://www3.uilsipo.si/PublicationServer/documentpdf.jsp?iDocId=2 5500\&iepatch=.pdf

[15] Slovenian Intellectual Property Office. (2019). SI 25646 A. A System and Method for printing and delivering Publications such as Newspapers ondemand. http://www3.uil-sipo.si/PublicationServer/ documentpdf.jsp?iDocId=44117\&iepatch=.pdf

[16] Plomer, A. (2017). The EPO as a Patent-law maker in Europe, European Law Journal. 25, 1, (Jan. 2017), 57-74. DOI= https://onlinelibrary.wiley.com/ doi/10.1111/eulj.12304

[17] European IP Helpdesk. (2020). Copyright or Patent how to protect my Software? https://www.iprhelpdesk.eu/news/copyright-orpatent-how-protect-my-software

[18] IPEG. (2011). Computer Implemented Inventions in Europe. An Update. https://www.ipeg.com/ computer-implemented-inventions

[19]EUR-Lex. Access to European Union Law. (2009). Directive 2009/24/EC of the European Parliament and of the Council of 23 April 2009 on the legal protection of computer programs.

https://eur-lex.europa.eu/legal-content/EN/TXT/ ?qid=1598852616560\&uri=CELEX:32009L0024

[20] Copyright and Related Rights Act (Official Gazette of the RS No. 16/07, 68/08, 110/13, 56/15, 63/16 ZKUASP and 59/19). http://www.pisrs.si/ Pis.web/pregledPredpisa?id=ZAKO403

[21] Trampuž, M. (2009). Source Code of Computer Program in Works made for hire. Pravna praksa. 15, 6-8.

[22] Supreme Court of the Republic of Slovenia, Judgment No. II Ips 153/2000 dated 23. 11. 2000.

[23] Trampuž, M., Oman, B., Zupančič, A. (1997). Copyright and Related Rights Act with Commentary. GV Založba, Ljubljana, 280-281. 
